Revista de la Escuela de Ciencias de la Educación, año 13, nRo. 12, vol. 2, Julio a diciembre de 2017. Páginas $149-166$. ISSN 1851-6297. ISSN 2362-3349 (EN LINEA). INSTITUCIÓN E INDIVIDUO EN TENSIÓN. EL PROCESO DE CAMBIO EN LA FORMACIÓN permanente del profesorado. Estudio de caso. Maria Soledad Manrique.

\title{
INSTITUCIÓN E INDIVIDUO EN TENSIÓN. EL PROCESO DE CAMBIO EN LA FORMACIÓN PERMANENTE DEL PROFESORADO. ESTUDIO DE CASO
}

\author{
María Soledad Manrique* \\ Universidad de Buenos Aires, Argentina \\ solemanrique@yahoo.com.ar
}

Recibido: 29/09/2016 Aceptado: 22/11/2016

\begin{abstract}
Resumen
El presente trabajo completa el planteo de un trabajo previo en relación con una cuestión clave a la hora de pensar la formación permanente del profesorado: la relación del docente con la institución de la cual forma parte. Buscamos dar cuenta de las tensiones entre ambos polos y de las posibilidades y de las dificultades para la transformación. Con este fin, tomamos como estudio de caso el proceso de una docente con muchos años de ejercicio en una institución de educación infantil, que participó en un dispositivo de formación que se llevó a cabo en dicha institución en el año 2011 en el marco de un proyecto de investigación del CONICET. El corpus está conformado por una serie de 6 entrevistas y los registros de la participación de la docente en los 11 encuentros de los grupos de reflexión llevados a cabo a lo largo de cuatro meses y en 4 clases observadas - dos al inicio y dos al finalizar el proceso. El material videofilmado, transcripto en detalle y analizado a través del análisis de Contenido (Krippendorf, 1990), el método comparativo constante (Glaser \& Strauss, 1967) y el análisis del discurso (Kerbrat - Orecchioni, 1986) fue luego reinterpretado desde la perspectiva del análisis institucional y de la psicología psicoanalítica.
\end{abstract}

Licenciada en Ciencias de la Educación y Doctora por la Universidad de Buenos Aires y Psicodramatista. Fue becaria doctoral y posdoctoral del CONICET e Investigadora Asistente. Actualmente, como Investigadora Adjunta del CONICET se especializa en el área de formación de adultos y transformación subjetiva, con publicaciones nacionales e internacionales en el tema. Es docente, Jefe de Trabajos Prácticos en la Cátedra de Didáctica II de la Carrera de Ciencias de la Educación, Facultad de Filosofía y Letras, UBA. 
Revista de la Escuela de Ciencias de la Educación, año 13, nRo. 12, vol. 2, Julio a diciembre de 2017. Páginas 149-166. ISSN 1851-6297. ISSN 2362-3349 (EN LÍNEA). INSTITUCIÓN E INDIVIDUO EN TENSIÓN. EL PROCESO DE CAMBIO EN LA FORMACIÓN permanente del profesorado. Estudio de caso. Maria Soledad Manrique.

Palabras clave: Formación docente permanente - Tensión individuo institución - Transformación subjetiva - Procesos intrasubjetivos - Análisis institucional.

\section{Abstract}

This work completes the study of a previous publication in relation to a key issue when thinking about teacher training: teacher's relationship with the institution he or she is part of. We seek to account for the tensions between the two poles and the possibilities and difficulties for transformation. To this end, wepre sent a case study of a teacher with many years'practice at an institution of children education. The teacher participated in a training program that took place at that institution in 2011, under a CONICET research project. The corpus is comprised of a series of 6 interviews and records of the participation of teachers in the 11 meetings of focus groups conducted over four months and in 4 classes observed (two at the beginning and two at the end the process). The filmed material, transcribed in detail and analyzed through content analysis (Krippendorf, 1990), the constant comparative method (Glaser\& Strauss, 1967) and discourse analysis (Kerbrat - Orecchioni, 1986) was then reinterpreted from the institutional analysis and the psycho analitic perspective.

Key words: Permanent teacher education - Tension between individual and institution - Subjective transformation - Intrasubjectiveproceses - Institutional analysis.

\section{Introducción}

El cambio es uno de los efectos que tiene la formación en los docentes. Puede manifestarse en diferentes áreas. Si lo consideramos desde una perspectiva ligada a lo intersubjetivo el cambio puede estar asociado a los vínculos humanos entre compañeros, con las autoridades, o con los propios alumnos. En el área lo intrapsíquico puede implicar cuestiones como la percepción sobre uno mismo, nuevas maneras de manifestación del deseo o de otras emociones o la toma de conciencia de las mismas. Desde el punto de vista cognitivo también podemos pensar el cambio en lo que Zeichner (1994) denomina esquemas de percepción, valoración y acción y en los modelos mentales (Mevorach \& Strauss, 2012; Wilke, 2008). Cuando estos se modifican los individuos comprenden diferente las situaciones y toman otras decisiones en el día a día de sus prácticas. Ahora bien, estas prácticas tienen lugar en instituciones que tienen el potencial de funcionar como un regulador social interno del comportamiento individual, es decir, de convertirse en parte de la subjetividad (Fernández, 1994). 
Revista de la Escuela de Ciencias de la Educación, año 13, nRo. 12, vol. 2, Julio a diciembre de 2017. Páginas $149-166$. ISSN 1851-6297. ISSN 2362-3349 (EN LINEA). INSTITUCIÓN E INDIVIDUO EN TENSIÓN. EL PROCESO DE CAMBIO EN LA FORMACIÓN permanente del profesorado. Estudio de caso. Maria Soledad Manrique.

En este marco nos preguntamos ¿Qué pasa cuando algo de la índole de lo nuevo es construido por un individuo y altera el comportamiento de este individuo que era funcional a dicha institución? ¿Qué pasa cuando esto nuevo no se condice con los valores internalizados por el individuo, provenientes de la institución? ¿Qué pasa en ese vínculo intersubjetivo entre el individuo y la institución y qué pasa intrasubjetivamente con el individuo que continúa trabajando allí? ¿Qué pasa cuando una experiencia de formación es la responsable de propiciar esta situación?

El trabajo que aquí se presenta pretende empezar a responder a estas preguntas. Para hacerlo presentamos un estudio de caso extraído del corpus total de un proyecto perteneciente al CONICET que desde 2011 estudia procesos de formación en docentes en ejercicio en el Nivel Inicial. El caso que presentamos para este trabajo constituye un seguimiento clínico en profundidad de una docente en ejercicio a lo largo de una experiencia de formación que tuvo lugar en la propia institución de trabajo. Fue seleccionado porque en él se pone de manifiesto de manera particular esta tensión entre el individuo y la institución en la que nos interesa hacer foco.

\section{Conceptos marco}

Una forma posible de organizar la información de nuestro medio es distinguir diferentes ámbitos en todo fenómeno humano: individual, interpersonal, grupal, organizacional y social general. En trabajos previos hemos puesto la mirada sobre la formación en términos de proceso individual e interpersonal (Manrique, 2016; Manrique \& Mazza, 2016; Manrique \& Sanchez Abchi, 2015). En el análisis del caso que presentamos, circunscribimos únicamente a estos niveles supondría dejar de lado multiplicidad de fenómenos que son altamente relevantes para comprender el proceso de formación que esta docente enfrentó, el sentido que cobró para la docente y las oportunidades que el dispositivo de formación ofreció. Por ello hemos extendido la mirada al nivel institucional e incluso al nivel social para dar cuenta del proceso que tuvo lugar.

En el proceso de cambio que se busca favorecer con la formación, los esquemas de percepción valoración y acción (Zeichner, 1994) que conforman los modelos mentales (Mevorach \& Strauass, 2012; Wilke, 2008) de las docentes participantes podrían verse modificados. Estos esquemas son definidos como aquellos marcos que permiten otorgar sentido al entorno y tomar decisiones en ellos, es decir que subyacen a las prácticas de enseñanza y al desempeño docente. Ahora bien, estos esquemas que son individuales se conforman al interior de los grupos en función del espacio simbólico e imaginario que los grupos componen como sistema de interpretación del mundo y de la vida colectiva. A estos sistemas de interpretación del mundo que son colectivos, Castoriadis (1989) los denomina "significaciones imaginarias sociales" por tratarse de creaciones. Las significaciones imaginarias sociales se constituyen 
en esquemas organizadores que definen las coordenadas de lo pensable para esa sociedad, institución o grupo. Son aquello por medio de lo cual los individuos son producidos como individuos sociales capaces de participar en el hacer y en el decir de ese colectivo. Operan en lo implícito. Lo manifiesto de esas significaciones sociales es lo que se denomina ideología. Se trata de una elaboración racionalizada de dicha entidad imaginaria. Conservan lo instituido pero también conllevan la potencialidad instituyente. Algunas de estas significaciones son centrales, es decir, en torno a ellas se organiza todo un grupo de significaciones. Estos imaginarios sociales permiten el anclaje identitario con las instituciones y a la vez producen subjetividad. Las normas que regulan las instituciones, y que son una traducción de las del marco social más amplio configuran la trama de vínculos en las que se hace posible para cada uno identificarse con otros y con el grupo. De acuerdo a Castoriadis (1989) estas normas se internalizan como normas internas, tal como veremos que sostiene también desde otra perspectiva Bernstein (1990).

La potencia reguladora de las instituciones internalizadas deviene del hecho de que estas se apoyan en vínculos internos con las primeras imágenes de autoridad, como el padre. Esta autoridad se asienta en los miedos más arcaicos asociados a desobedecer las órdenes: miedo a perder el amor, al abandono, a dejar de existir; y se ligan a la culpa y al remordimiento por la transgresión. Este núcleo originario funciona como organizador de la conducta en relación con las subsiguientes normas sociales que se hacen propias. Violar los marcos que establecen las instituciones acarrea, pues, el riesgo imaginario de ser expulsado y considerado un extranjero en relación con el grupo social. De esta amenaza surge el poder regulador. Cuando esta regulación fracasa el conjunto ejerce su poder de vigilancia y castigo (Foucault, 1984) a través de formas sociales de protección de lo establecido. De allí la peligrosidad de ir en contra de estas normas y el costo que hay que pagar por hacerlo. Si el sujeto se ajusta a las normas impuestas encuentra la oportunidad de obtener seguridad y pertenencia, si no lo hace puede sufrir enajenación, exclusión y sufrimiento.

En relación al vínculo del individuo con las instituciones Berenstein (2004) plantea la pertenencia subjetiva de cada persona a tres mundos diferentes: el mundo socio-cultural, el mundo vincular y el mundo interno. Cada uno de estos mundos establece sus propias demandas que determinan al sujeto. Si bien se superponen en el individuo, tienen cierta autonomía relativa; lo cual significa que entre ellos puede existir cierta tensión. En cada uno de estos mundos existen aspectos inconscientes. En el mundo social, lo inconsciente involucra las reglas de circulación de la información y los sentimientos de incertidumbre ante la amenaza permanente de disolución del conjunto. Las creencias y certezas que provienen de este marco social no son cuestionadas sino que funcionan como un prejuicio - un juicio previo que no requiere constatación; 
Revista de la Escuela de Ciencias de la Educación, año 13, nRo. 12, vol. 2, Julio a diciembre de 2017. Páginas $149-166$. ISSN 1851-6297. ISSN 2362-3349 (EN LINEA). INSTITUCIÓN E INDIVIDUO EN TENSIÓN. EL PROCESO DE CAMBIO EN LA FORMACIÓN permanente del profesorado. Estudio de caso. Maria Soledad Manrique.

constituyen una base para el sentimiento de lo obvio. Esto obvio que se sostiene individualmente, a su vez, y es vivido por el individuo como algo personal, a su vez lo habilita a formar parte de ese conjunto. Además, "lo obvio", al ser compartido, tiende a fijarse.

Por otro lado Berenstein (2004) señala que estas creencias circunscriben lo visible para el sujeto. Es desde el significado que se hace posible la percepción. Las creencias pueden, pues, constituir un claro obstáculo al cambio. Son compartidas a partir de un vasto sistema de imposición por el cual el sujeto se asegura vivir con la aceptación del conjunto social, y se identifica, elaborando de alguna manera esta imposición.

Las distintas formas de subjetividad- la que es producto de las marcas infantiles y la que es producto de las experiencias actuales- persisten juntas sin necesidad de formar entre ellas una unidad. No obstante, cada vez que hay novedad en un vínculo se instituye un nuevo sujeto.

Hasta ahora venimos refiriéndonos a los individuos y su vínculo con las instituciones. Si para observar el mismo fenómeno tomamos, ahora, el punto de vista de las instituciones y las relacionamos con los individuos, partiremos de la teoría de Bernstein (1990) según la cual el poder es aquello que rompe la homogeneidad del espacio macro social y clasifica, distribuye y separa. De tendencia claramente marxista, este autor ha mostrado cómo del conjunto social no homogéneo, algunos sectores usufructúan de los bienes materiales y sociales y de los derechos sobre estos, en mayor medida que otros. Las reglas que rigen esta distribución de bienes a nivel macro se traducen a nivel micro dentro de cada una de las instituciones. Es decir, que cada institución encuentra una forma particular de reproducir parte de la configuración social general y formas particulares de legitimar y garantizar esta configuración social. Los establecimientos educativos, en particular, sufren la demanda de mandatos paradójicos (Fernández, 2007): educación para todos - selección de algunos; promover liberación - promover adaptación al sistema; enriquecer al individuo - alimentar al sistema. La forma de reproducción de esas reglas macro a nivel micro tiene que ver con cómo para responder a estos mandatos las instituciones producen una cierta división del trabajo y una asignación diferencial de poder. Al respecto Fernández (2007) mostró que las escuelas Argentinas incluidas en su estudio mantenían la desigualdad a través de defensas que involucraban la negación, la racionalización, el desplazamiento y el encubrimiento ideológico de las dificultades bajo la forma de idealización y externalización de responsabilidades. Los reglamentos oficiaban de aliados con la evitación del análisis de las situaciones e impedían tomar decisiones acordes a cada circunstancia.

De acuerdo a Bernstein (1990) la posibilidad de la traducción de la forma que toma la distribución de bienes de lo macro a lo micro radica, en parte, en que los individuos no son conscientes de que esto sea así. Lo establecido 
conforma una trama que encubre la violencia de esta expropiación y permite que sea considerada algo natural. En este sentido, para el autor la toma de conciencia resulta un modo de enfrentar la enajenación. Sin embargo, la operación de explicitación suele ser resistida por el riesgo que implica la liberación de tendencias instituyentes (Fernández, 1994).

Ahora bien, el estilo institucional - el modo que caracteriza la manera de producir, provocar imágenes y resolver conflictos - puede dar más o menos lugar a esta explicitación de cómo están distribuidos los bienes y a quienes beneficia la distribución. Bleger (1964) define la dinámica institucional como la capacidad de plantear las dificultades como problema, discriminar necesidades y ensayar soluciones posibles, en lugar de hacerlo de manera dilemática, esto es en términos paradójicos que clausuran todo intento de solución. Esta capacidad de problematizar caracteriza lo que Fernández (1994) ha denominado como la modalidad progresiva de funcionamiento institucional, contrapuesta a la modalidad regresiva.

Resumiendo, tal como muestran las teorías que abordan la intersección de lo individual y lo institucional que hemos seleccionado, las significaciones provenientes del mundo intrasubjetivo y las derivadas de la trama relacional de los sistemas de poder conforman un entramado. Es en este entramado que debemos comprender el proceso de formación de un docente que tiene lugar al interior de una institución educativa.

En este trabajo nos preguntaremos precisamente en qué sentido el dispositivo de formación altera la dinámica de relación del individuo con la institución y qué relación hay entre el cambio en las participantes del dispositivo y el cambio institucional. Por otro lado nos preguntaremos en qué medida este vínculo con la institución afecta las posibilidades de formación de ese individuo que se encuentra inserto en ella y regido por sus reglas.

\section{Metodología \\ Participantes}

En el marco del proyecto de investigación - acción de CONICET "Formación docente y transformación subjetiva. El cambio en los modelos mentales y en la práctica pedagógica en el Nivel Inicial" que se viene llevando a cabo desde 2011 se diseñó e implementó el dispositivo de formación "VERSE". Tuvo lugar en dos Jardines de Infantes ubicados en una zona marginal del Partido de Tigre, provincia de Buenos Aires, Argentina, con un total de 14 docentes que prestaron su consentimiento. Las instituciones cuentan con un alumnado de un total de alrededor de 90 niños cada una de entre 3 y 5 años que asisten durante 8 horas y un apoyo escolar, una de ellas, por la tarde, con 60 niños de 6 a 11 años.

Para este estudio se toma una de las dos instituciones, en las cuales se trabajó con el total de las docentes (8) de salas de 2, 3, 4 y 5 años (2 do- 
Revista de la Escuela de Ciencias de la Educación, año 13, nRo. 12, vol. 2, julio a diciembre de 2017. Páginas 149-166. ISSN 1851-6297. ISSN 2362-3349 (EN LINEA). INSTITUCIÓN E INDIVIDUO EN TENSIÓN. EL PROCESO DE CAMBIO EN LA FORMACIÓN permanente del profesorado. Estudio de caso. Maria Soledad Manrique.

centes por sala, una cumpliendo un rol pedagógico como docente y la otra cumpliendo un rol administrativo como preceptora) y la directora suplente de la institución. Al momento de la toma de datos en 2011 se nos informa que la institución había surgido como "Guardería", con una función asistencial y había sido cedida junto con sus tierras por el municipio de Tigre al Obispado hacía 21 años. Hacía 7 años, en coincidencia con el asfaltado de las calles se había convertido en Jardín de Infantes oficial, dependiente del Ministerio de Educación, asumiendo como central la función pedagógica.

Para el corpus del trabajo se consideran particularmente las 3 entrevistas en profundidad a la directora suplente, los 11 encuentros grupales de formación y los 6 encuentros individuales de formación de la docente tomada como estudio de caso ( 7 horas de entrevista a la docente). Se trata de la docente que ocupa el rol de preceptora asistente en sala de 4 años. La sala tiene 28 alumnos que provienen de grupos socioculturales y socioeconómicos desfavorecidos. Viven en el mismo barrio donde se encuentra la escuela. Sus padres cuentan con una educación básica que en la mayoría de los casos no alcanza la secundaria. La docente - preceptora, a quien de ahora en más nos referiremos con el nombre ficticio de Carla ha vivido siempre en el mismo barrio que la población de la escuela, y ha tenido una educación similar en su infancia. Sin embargo desde su ingreso a la institución hace 20 años como madre cuidadora, cuando pasó a depender del Obispado, se ha ido formado, pudiendo completar primero sus estudios secundarios y más tarde los terciarios en el profesorado, instada por la institución.

\section{Instrumentos}

El dispositivo de formación en el que participaron las 8 docentes y la directora suplente duró 4 meses, con instancias individuales (6 entrevistas de 40 - 60 minutos) y grupales (11 reuniones de 60 minutos). La instancia individual implicó la visualización en video y análisis de cada docente de su propia práctica en dos actividades típicas del Jardín de Infantes relacionadas con la narrativa infantil: la ronda en la que los niños relatan experiencias personales y la lectura de cuentos -ambas situaciones videofilmadas al comienzo de la participación en el dispositivo.

En la primera entrevista individual se proyectó a cada docente la filmación de la actividad durante la ronda en la que los niños relataban experiencias personales y se fue deteniendo la filmación en algunos momentos para que esta pudiera ir realizando comentarios sobre la misma, en un procedimiento similar al realizado por Clot (2006), al que se denomina autoconfrontación simple. La docente luego se llevó una versión transcripta de esta situación y un cuestionario con preguntas para guiar el análisis de la situación, focalizando en las intervenciones docentes y en el desempeño infantil que parecía haberse favorecido en ambas situaciones de enseñanza. En la segunda entrevista 
la docente y la formadora intercambiaron acerca de este análisis. En la tercera y cuarta entrevistas se repitió el procedimiento para la actividad de lectura de cuentos, también videofilmada al inicio.

Los 11 encuentros grupales tuvieron la modalidad de taller y se enfocaron en actividades que implicaban la reflexión acerca de las estrategias docentes y su relación con los procesos infantiles que se ponían en juego. Para este fin nos valimos de juegos, role-play, videos, lecturas, debates, etc. Se proporcionó material teórico como apoyo de lectura optativo en relación a los temas que se iban presentando.

\section{Procedimiento de recolección y análisis}

Se transcribieron en profundidad (Taylor \& Bogdan, 1987) los 11 encuentros grupales videofilmados, las 6 entrevistas con la docente y las 3 entrevistas con la directora suplente. Dentro de una lógica cualitativa el análisis se llevó a cabo a través de la combinación de las técnicas de Análisis de Contenido (Krippendorf, 1990), el Método Comparativo Constante (Glaser \& Strauss, 1967), y el Análisis del Discurso (Kerbrat - Orecchioni, 1986; Manrique, 2014). Se crearon categorías inductivas que se agruparon en tres dimensiones de análisis:

-La dimensión de las representaciones que conforman los modelos mentales de la docente: sobre los niños y su desarrollo, el grupo a su cargo, el rol docente, lo que implica enseñar y aprender, sobre los relatos de experiencias personales y la situación de ronda, sobre los cuentos y la situación de lectura, acerca del dispositivo de formación, la formadora y sobre sí misma.

-La dimensión de los procesos que tuvieron lugar durante la experiencia de formación: dimensión que no describiremos en detalle ya que no nos detendremos en este trabajo en ella.

-La dimensión de los procesos intrasubjetivos: de tipo cognitivo; de tipo metacognitivo; de tipo emocional.

Cada una de estas dimensiones incluye cuestiones manifiestas (lo que la docente o directora dicen de sí) así como cuestiones no manifiestas que constituyen inferencias del analista basadas en evidencia empírica.

Con el conjunto de estos resultados se realizó un análisis final de tipo clínico que permitió elaborar hipótesis más abstractas basadas en estas primeras de carácter inductivo, desde categorías provenientes de las perspectivas antes expuestas: una perspectiva psíquica (Bernstein, 1990), una perspectiva institucional (Fernández, 1994; Castoriadis, 1989) y una sociológica (Bernstein, 1990; Foucault, 1981).

\section{Resultados}

Presentaremos una descripción resumida de los modelos mentales de Carla que han permanecido inalterados, y aquellos que se han modificado y luego 
Revista de la Escuela de Ciencias de la Educación, año 13, nRo. 12, vol. 2, julio a diciembre de 2017. Páginas 149-166. ISSN 1851-6297. ISSN 2362-3349 (EN LINEA). INSTITUCIÓN E INDIVIDUO EN TENSIÓN. EL PROCESO DE CAMBIO EN LA FORMACIÓN permanente del profesorado. Estudio de caso. Maria Soledad Manrique.

discutiremos a través de las teorías consideradas en qué sentido este cambio afectó la relación de Carla con la institución y de qué modo esta relación con la institución parece haber afectado la posibilidad de cambio en Carla.

\section{Modelos mentales que se mantienen inalterados a lo largo de todo el proceso}

Habiendo transitado 21 años de su vida en la Institución, Carla considera que su vida personal se encuentra intrincablemente unida a los procesos de la institución, señalando que sus crisis personales y los momentos de cambio en la institución han confluido siempre. Ejemplifica con su propio ingreso a la institución como producto de una etapa de crisis al salir de un cáncer y una operación a los 18 años, que coincidió con el momento en que la antigua Guardería pasó de manos municipales a depender de la Parroquia. Como hija de una catequista ella fue aceptada como "mamá cuidadora" voluntaria. El segundo hito que cita es el momento en que se divorcia, cuando le empiezan a insistir que complete sus estudios como condición para continuar en la institución ya que la misma pasaría a ser un "Jardín de Infantes" en el futuro. Ella retoma sus estudios secundarios y cursa el profesorado, concluyéndolo pasados los 30 años. Por último señala el momento en que -hace 7 años- la Guardería se convierte en Jardín oficial, y ella es efectivamente contratada como preceptora, dejando su rol de madre cuidadora, debido a que cuenta con título docente.

Carla describe a la institución como transitando un momento de búsqueda de equilibrio entre dos funciones: su antigua función asistencial como "Guardería" (previa a la "Ilegada del asfalto") y su nueva función pedagógica, con el ingreso de una nueva directora (actualmente de licencia por maternidad). En el modelo mental de Carla la función pedagógica de la Institución está asociada a una idea de progreso "En su momento había menos trabajo, acá, era una comunidad más chata, ahora se levantó un poco, a raíz de que vino el asfalto y eso es como que empezó la comunidad a querer salir adelante. Tenemos las villas, todo, pero como que la gente cambió su forma de vivir." Carla también plantea que de todas maneras en la institución sigue primando lo que ella llama "la mística de la guardería" y que la comunidad aún prioriza lo asistencial -"Que los nenes estén cubiertos, que no estén en la calle/ Les cuesta tomar conciencia de que lo pedagógico es importante también/ Todo el mundo sigue pensando que es guardería el Jardín, por eso algunos se enojan cuando vienen a anotar... muchas de las mamás que están hoy fueron alumnas mías." Ella habla de algunas de estas madres en términos despectivos, emplea los términos "nula" o "bruta" para referirse a ellas.

Al caracterizar a la comunidad se refiere a la dificultad para enfrentar el cambio - "También es una comunidad que le cuestan los cambios. Costó mucho el cambio de una directora a otra." Carla se considera como parte de la comunidad y se identifica con ella, no solamente porque vive desde que 
nació a dos cuadras de la escuela: "estoy muy pegada al barrio, es parte de mí" / La mía no es tanto la mirada solamente como docente sino más como comunidad, como otro perfil (comparándose con las otras maestras)". Carla se percibe a sí misma como siendo respetada por su comunidad. "Si bien esta comunidad son de nenes bajos, no son tan irrespetuosos como los otros nenes. Esta gente que menos tiene me parece que me respeta más que el que más tiene o el que está un poquito mejor..."

Como parte de esta población subestimada, los niños son considerados como deficientes en varios sentidos: son considerados individualmente como la causa de los conflictos debido a sus deficiencias afectivas y sociales - "Tiene una falta de atención de su papá importante y lo vuelca todo. Necesitan cariño/ Están los que están quietos y los que molestan" -. Son considerados, también como casos para ser "tratados por un psicólogo", cuando "no acatan nunca" y una amenaza potencial para el docente y para otros niños - "Te pasan por arriba. / Te pisan la cabeza. / Lastiman al otro."En relación con ellos". manifiesta el miedo que le provocan - "La que sí más como miedito me da es la sala de 5 ...no me animaría (a tomar la sala)" -.

Por un lado la subestimación de los niños se encuentra asociada a la función que Carla describe como asistencialista de la institución dentro de la cual es fundamental "dar cariño". Aparece también la segunda función que Carla subraya: la función disciplinadora: "tenerlos abrazados para que no se desbanden". Esta función de contención puede ser pensada tanto desde el punto de vista del afecto como desde el control disciplinario, como se entiende la contención en el ámbito hospitalario o de la salud. Se trata de un control o "contención" que sería ejercido en pos del cuidado: se abraza al niño para que no lastime a otros, como un modo de sujetarlo.

Por otro lado, la subestimación de los niños coincide totalmente con la subestimación de Carla sobre sí misma como parte de dicha comunidad. Al igual que cuando se refiere a los niños, se describe a sí misma a través de juicios de valor negativos - "Me siento como insegura ¿Se lo estaré narrando bien? / No me veo bien para lo pedagógico" - y en términos de inferioridad con respecto a sus compañeras docentes - "Aprendo mucho de ellas / Nunca pensé que me iba a tirar la propuesta a mí, pensé para el resto y no para mí (en relación con la posibilidad de tomar el cargo de docente de la sala), o sea yo como siempre, nunca... pasa esto que te cuesta" -. Si bien le han ofrecido tomar una sala a su cargo como docente en varias oportunidades, solo durante un año lo aceptó -"no estaba preparada para estar en la sala. No estoy bien, no es justo para los nenes." - Aun contando con título docente y luego de 20 años en la institución ella no se siente competente para la docencia - "Cuando fui maestra me equivoqué mucho". Esta imagen negativa de sí se mantiene cuando Carla realiza la actividad de verse en video realizando las actividades - "No me reconozco / No era yo / No me gusté". Sensaciones todas que dan cuenta 
Revista de la Escuela de Ciencias de la Educación, año 13, nRo. 12, vol. 2, Julio a diciembre de 2017. Páginas $149-166$. ISSN 1851-6297. ISSN 2362-3349 (EN LINEA). INSTITUCIÓN E INDIVIDUO EN TENSIÓN. EL PROCESO DE CAMBIO EN LA FORMACIÓN permanente del profesorado. Estudio de caso. Maria Soledad Manrique.

del rechazo que le produce su propia imagen comparada siempre con un ideal que no se satisface - "No me gustó nada porque no es la Carla que tiene que ser" -. El juicio de valor negativo sobre sí misma se interpone en el análisis de aquello que ve; es decir, al prestar atención a la falta - "me faltó hacerles el cierre del cuento" - deja de lado otras cuestiones relevantes y también sus propias potencialidades. Esta representación de sí cargada de valoración negativa continúa estando presente al final de la experiencia formativa cuando se evalúa a sí misma. - "No me gusta ser la que está todo el tiempo poniendo un límite/ Vos te ves en un video, vos decís "bueno, no". No me gustó verme desde ahí".

En su relación con la institución Carla reconoce haber crecido junto con la institución y se siente en deuda con todo lo recibido. Reconoce estar cumpliendo un rol diferenciado tanto de las maestras como de las otras preceptoras. Consiste en garantizar esa segunda función de la institución que mencionamos: el cumplimiento de la disciplina a través de formas de coerción como la amenaza y la sanción - "Carla andá a retar a Fulano, andá a retar a... /Aparte yo tengo esa voz y soy grandota y vengo y aparte con un grito mío imaginate que se calla medio jardín. Como que me tienen en esa función y a veces me sirve porque me traen los nenes con más problemas de conducta" -. Se trata de un rol que siente que se le adjudica desde la institución y que ella misma acepta. La hace sentir valiosa e idónea - “iSi no voy yo, ni se duermen!”.

Es nuestra hipótesis que el desempeño de este rol se apoya en necesidades intersubjetivas - vinculadas con la pertenencia a la comunidad y a la institución - y en necesidades intrasubjetivas. Desde lo intersubjetivo se ligaría a la necesidad institucional que Carla identifica como un requisito para que los niños "sientan acá un lugar donde estar bien", que tiene que ver con garantizar su cuidado. Dado que considera a los niños como peligrosos es menester cuidarlos de sí mismos "para que no se maten". Hasta el final de la experiencia de formación Carla sostiene la legitimidad del ejercicio de ese rol - "alguien tiene que retarlos". El ejercicio de la coerción, que es el único modo que se le ocurre de poner límites, se vincula con la función asistencial de la institución que antes describimos. Por otro lado este rol que reconoce que desempeña está relacionado también con la tarea que siente le atribuyen otros miembros de la institución y por lo cual la valoran.

Desde el punto de vista intrasubjetivo, el desempeño del rol de disciplinamiento responde a una serie de necesidades intrapsíquicas de Carla. En primer lugar la aceptación y reconocimiento del entorno antes descripta responde a la necesidad de ser aceptada, que funciona de sostén, a su vez, de una autoestima vulnerada (inferida de las representaciones de sí que antes citamos "para lo pedagógico no sirvo"). Otra de las necesidades que se satisface en el ejercicio de este rol es la de controlar su entorno, que está vinculada al temor por el desborde. Efectivamente Carla narra en relación con lo 
que ella considera amenazante de los niños, una experiencia traumática de su formación en la residencia en que los niños le hicieron "un piquete" por no "plantarse". Por lo dicho, podemos argumentar que el desempeño del rol parece proporcionarle a Carla seguridad frente a aquello que vive como amenaza potencial a su propia autoestima vulnerada.

Ambos tipos de necesidades satisfechas en el desempeño del rol - inter e intra psíquicas están asociadas a las representaciones de Carla que antes hemos descripto acerca de los niños, de la comunidad, de ella como parte de la comunidad, de la institución y de su propio rol en la misma, todos aspectos que componen su modelo mental. De esta manera Carla se convierte en portavoz, heredera, depositaria y responsable de los valores de la "vieja institución". Esta representación de sí como la garante de la función asistencialista y disciplinadora de la escuela se mantiene inalterada a lo largo de todo el proceso - "los acompaño desde ese lado, no sé si es porque yo empecé en este jardín con una metodología, con un pensamiento también por ser de la iglesia y del pensamiento que tiene la iglesia". Estos valores originarios estarían siendo salvaguardados por un miembro que los porta desde sus orígenes. Esto también se evidencia en el carácter compartido de esta representación al interior de la institución y de la comunidad. Efectivamente sus compañeras docentes la llaman en broma "vicedirectora" a partir de un grupo de madres que le adjudicó este título que en la institución no existe.

\section{Modelos mentales de Carla que se van modificando}

En el primer mes de la experiencia de formación Carla comienza a prestar atención a aspectos que antes no consideraba; sus modelos mentales empiezan a incluir la importancia de que los niños expresen sus experiencias y que puedan comunicarse con ella.

En relación con la representación de los niños ya no hay una depositación de las dificultades exclusivamente en la esfera individual de ellos como al comienzo, sino una mirada que integra más cantidad de factores y una lectura de la situación en términos de vínculo. Este nuevo esquema de percepción implica relacionar la falta de comunicación de los niños - antes atribuida a una carencia individual - con el posicionamiento de la escuela y de ella misma dentro de esta: "me ven en otro lado, como la que los reta". Esta idea denota también que se está incorporando la percepción de la situación desde otras posiciones, además de la propia; en este caso el punto de vista de los niños mismos. Ambas cuestiones - el integrar mayor cantidad de factores en la mirada y el posicionarse en otros lugares para mirar, parecen contribuir con una toma de conciencia de que el vínculo de amenaza entre los niños y ella no favorece la función comunicativa que se ha convertido en un objetivo deseable. En este marco, el ejercicio del rol disciplinario comienza a ser interpretado por Carla como un obstáculo "(los niños) no se animan"; se carga de una con- 
Revista de la Escuela de Ciencias de la Educación, año 13, nRo. 12, vol. 2, Julio a diciembre de 2017. Páginas $149-166$. ISSN 1851-6297. ISSN 2362-3349 (EN LINEA). INSTITUCIÓN E INDIVIDUO EN TENSIÓN. EL PROCESO DE CAMBIO EN LA FORMACIÓN permanente del profesorado. Estudio de caso. Maria Soledad Manrique.

notación negativa y comienza a ser cuestionado: "Que digan Carla es mala, esta siempre enojada... si un nene está pensando eso de mí, ya chau ¿Viste? entonces, una cosa es que vos vengas y los retes y te hagas la mala y otra cosa es que el chico ya te vea de esa manera". La imagen de sí sancionando que antes le deparaba aceptación y respeto, ya no se sostiene como ideal. El trabajo con la propuesta de formación pone en visibilidad la contradicción entre el ejercicio de un rol puramente sancionador y la posibilidad de encuentro real con los niños, que empieza a ser valorada.

Acompañando lo mencionado, se producen cambios en sus esquemas de acción que la llevan a "bajar al nivel de ellos" - escucharlos más y sancionar menos -, que producen efectos inmediatos en la interacción con ellos, que según ella la "sorprendieron" y que ella misma asocia con la confianza que habrán sentido hacia ella. Los niños le hablan más de lo que suelen hacerlo. Esta situación le agrada y contribuye a que cuestione aún más su posicionamiento previo en el desempeño del rol disciplinario.

Todo este movimiento va acompañado del surgimiento de una serie de contradicciones previamente inexistentes: entre el ejercicio del rol y cierto malestar - "Soy muy disciplinaria pero me cansa" - entre su deseo de cambiar y las dificultades de ese cambio, que en su caso se asocian a lo que vive como las expectativas de su entorno - "Hay cosas que me molestan pero no puedo hacer un cambio brusco porque yo estoy cambiando. No te puedo, yo no soy de venir y decirte "bueno listo mirá, yo esto no lo voy a hacer más, de ahora en más. Trato de ir gradualmente".

Parece haberse modificado el esquema de percepción sobre sí misma de Carla - "No me veía que era tan autoritaria" - así como su valoración sobre sí - "Generó en mí como persona, Carla, de verme en un montón de situaciones que no me quiero ver, que no me gusta o que yo creí que no estaba parada de ese lado. Y esto que ví, que evalué, que vos me mostraste, me sirvió mil veces para ver que estoy parada en una postura que no quiero estar. No me gusta ser la que está todo el tiempo retando, todo el tiempo poniendo un límite. Vos te ves en un video, vos decís "bueno, no". Ser tan estricta, tan exigente, y estar subida en un lugar que no quiero estar".

Otro de los cambios que se manifiesta es el grado de autonomía, Carla empieza a confiar en lo que ella misma percibe de sí, más allá de lo que el entorno le devuelve: "El taller me hizo un clic para ver cómo estaba yo, mi postura de trabajo, como era, o como se me veía de afuera. Yo no quiero que se me vea de esa manera. Tan autoritaria, tan exigente. Por ahí podrá ser otra (quien sanciona) pero yo no quiero estar en ese rol. Yo sé lo planteé a las chicas y me dijeron que no me ven que yo sea tan así y bueno pero es lo que yo sentí, lo que yo siento y a mí me pasa y hasta acá llegué, punto". En base a lo que dice parece haber tomado conciencia de que está respondiendo a una demanda externa y de hecho señala "yo en la sala soy muy diferente" (cuando 
le toca ocupar el rol docente). De todos modos, aun siendo consciente de esta demanda, le sigue pesando, como se ve en esta frase contradictoria al hablar del grupo de pares - "La verdad... tranquila ... me pone muy nerviosa... la verdad me siento como evaluada todo el tiempo".

Aparece, asimismo un reconocimiento de que hay un rasgo personal de necesidad de control en este rol que asume - "Me molesta que no... que hablen no,... o sea lo que me molesta es que hablen, sí"/ "Será porque es mi carácter, mi forma de ser, porque desgraciadamente tengo ... - por un lado es malo, por un lado es bueno - de saber lo que está haciendo el que está acá, allá y allá, el que se fue y el que entró y el que salió. No lo puedo evitar. Es algo mío, de Carla".

Esta toma de conciencia va acompañada de un replanteo reflexivo que implica ubicarse en la pregunta acerca de lo que quiere para sí misma. "Entonces, yo vengo de un año difícil, de cosas personales mías y estoy buscando un lugar donde poder terminar de ver qué cosas quiero y qué no quiero. Y esto yo te digo la verdad, a mí este taller en sí me sacó algo personal. No en lo que tiene que ver con lo estrictamente laboral... me estructuró desde otro lado y me hizo evaluar Carla personal, persona".

Hacia la última semana de la formación, si bien Carla manifiesta haber modificado sus esquemas de acción - "Sí sigo retando a algunos que otros pero por ahí le digo "no, llévatelo, no me lo mandes" - solicita que no se la filme más para evitar el sufrimiento que la situación le produce - "Me pasaron un montón de cosas que me siguen pasando y estoy tratando de canalizar en otro lado. Entonces, listo, ya está, hasta acá llegué. No me gusto, no soy yo misma".

\section{Discusión}

Los resultados muestran parte del proceso de transformación que tuvo lugar en una docente. Intentaremos reinterpretarlos desde las teorías de Fernández (1994), Fernández (2007), Bernstein (1990) y Berenstein (2004). Para eso ensayaremos una serie de respuestas a las preguntas planteadas en la introducción. ¿En qué sentido el dispositivo de formación altera la dinámica de relación del individuo con la institución y qué relación hay entre el cambio en una de las participantes del dispositivo y el cambio institucional? ¿En qué medida este vínculo con la institución afecta las posibilidades de formación de ese individuo que se encuentra inserto en ella y regido por sus reglas?

Nuestra primer hipótesis indica que habría inicialmente una relación de equilibrio entre los modelos mentales (Mevorach \& Strauss, 2012) individuales de Carla y las significaciones imaginarias centrales (Castoriadis, 1989), aquellos sentidos compartidos institucionalmente. Desde el punto de vista intrapsíquico no parecería haber tensiones entre los mundos social - cultural, vincular e interno en Carla (Berenstein, 2004). El aspecto obvio que se juega 
Revista de la Escuela de Ciencias de la Educación, año 13, nRo. 12, vol. 2, Julio a diciembre de 2017. Páginas $149-166$. ISSN 1851-6297. ISSN 2362-3349 (EN LINEA). INSTITUCIÓN E INDIVIDUO EN TENSIÓN. EL PROCESO DE CAMBIO EN LA FORMACIÓN permanente del profesorado. Estudio de caso. Maria Soledad Manrique.

en el mundo social-cultural y que es aceptado por Carla en su mundo interno es la necesidad de disciplinamiento de los niños como la función social más relevante asignada a la escuela. Queda, pues, legitimado para el grupo social y para sí misma el rol de Carla como disciplinadora. La coerción como forma de llevar a cabo este rol disciplinario es también un aspecto naturalizado que no se pone en cuestionamiento. Abordando la relación del nivel social con el individual (Bernestein, 1990) la naturalización de la coerción podría pensarse como aquello que socialmente es aceptado como premisa indiscutible y constituye la base para lo que individualmente es vivido por Carla como "lo obvio".

Esta coyuntura parece haber funcionado para Carla internamente como anclaje identitario y brindarle una sensación de seguridad y pertenencia, si consideramos su discurso al comienzo del dispositivo de formación, en términos de sentirse parte de la comunidad, respetada y valorando lo que le fue dado en ella. La institución, por su parte, encuentra en ella a la ejecutora de las acciones necesarias para poder efectivamente cumplir con la función de disciplinamiento, asignándole este rol que a su vez esta diferenciado del rol pedagógico, y del de las otras preceptoras.

Nuestra segunda hipótesis plantea que en el curso de la experiencia de formación tuvieron lugar transformaciones en los modelos mentales (Mevorach \& Strauss, 2012; Wilke, 2008) de la docente. Tomamos como evidencia empírica los datos presentados en los resultados, basados en su discurso y en sus acciones.

La tercera hipótesis que sostendremos es que estos cambios parecen haber producido tensiones que no tienen un precedente en el vínculo de la docente con la institución, una institución que ha cumplido para ella la función de formadora. En términos de Castoriadis (1989) podríamos pensar que el cuestionamiento de Carla sobre sus instituciones internalizadas estaría reflejándose también como cuestionamiento hacia la institución y algunas de las significaciones imaginarias centrales. A partir de la participación en el dispositivo, aquello que era vivido como obvio comienza a ser explicitado y cuestionado. Este cuestionamiento, a su vez, pone en duda la legitimidad de la función principal que se adjudicaba la institución y el rol de Carla como garante de la misma.

Desde el punto de vista intrapsíquico, resulta evidente el surgimiento de una controversia previamente inexistente en Carla en torno a los mensajes de sus mundos social, vincular e interno (Berenstein, 2004). El mensaje del mundo interno de Carla comienza a cuestionar el desempeño del rol disciplinador, avalado por sus mundos vincular y social. Esta tensión interna es manifestada por Carla como la causa por la cual ella no podría llevar a cabo cambios "tan bruscos". En este sentido se pone de manifiesto el poder regulador de las instancias internas (Fernández, 1994). Estas instancias internalizadas sobre los que se apoya su vínculo con la institución estarían, a su vez apoyándose 
en aspectos arcaicos, que en este caso toman la forma de temor a perder el amor de su entorno (Berenstein, 2004); un amor que es indispensable en tanto sostiene una autoestima vulnerada. Estos vínculos arcaicos estarían funcionando, entonces, en este caso, como obstaculizadores del cambio.

Desde el punto de vista institucional, el cuestionamiento de Carla puso de manifiesto la función paradojal de la escuela como promotora de la liberación y del enriquecimiento individual por un lado y la función de adaptación y de alimentación del sistema, por otro, que Fernández (2007) ya había observado. En este sentido el cuestionamiento puede ser interpretado como una tendencia instituyente (Bleger, 1964). Ante la tendencia instituyente presente en el cuestionamiento de aquello considerado obvio, se observó la aparición de lo que Foucault (1984) había mencionado como "formas de protección de lo establecido" para contrarrestarla. Tomaron la forma de la negación de lo que Carla planteaba acerca de su desempeño con algunas de las docentes como portavoces - "no sos tan autoritaria" y el traslado del conflicto a un plano de responsabilización individual, como si se tratara de un dilema que Carla sola debe resolver, que impide que se realice un análisis. Todo esto puede considerarse evidencia de una dinámica regresiva de funcionamiento institucional (Fernández, 1994).

Desde el punto de vista social es posible inferir de esta situación de formación, el modo en que estaría operando la reproducción a nivel micro de la distribución desigual de los recursos y del poder. La institución se propone como objetivo conseguir que los niños se adapten al sistema. Esta finalidad disciplinadora se ubica por encima de cualquier otro objetivo pedagógico y se encuentra incuestionada y naturalizada. El dispositivo de formación, al proponer otro tipo de jerarquías en relación a las propuestas pedagógicas - por ejemplo priorizar el desarrollo infantil y la expresión -, cuestiona las bases del sistema. Los modelos mentales de la docente que participa en el mismo se transforman y la docente encarna en su propio proceso el encuentro entre estas dos lógicas. Ante esta situación se ponen en evidencia los mecanismos con los que cuenta el sistema para mantener el status quo, de los que hablan Bernstein (1990), Castoriadis (1989) y Foucault (1984), mecanismos que ponen en evidencia la funcionalidad de la escuela al servicio de la reproducción social. Considerar el entramado entre estos tres niveles - social, institucional y personal nos permite comprender las dificultades para la transformación que la docente experimenta a nivel personal.

Resumiendo, el caso analizado pone de manifiesto la dinámica entre un docente en el proceso de transformarse al participar de una experiencia de formación y cómo en esa transformación afecta a la institución de la cual es parte, generando tensión. El trabajo muestra la forma que toma esta tensión en términos intersubjetivos en el grupo e intrasubjetivamente en cuanto a instituciones internalizadas por la docente. Muestra, asimismo, el movimiento ins- 
Revista de la Escuela de Ciencias de la Educación, año 13, nRo. 12, vol. 2, julio a diciembre de 2017. Páginas 149-166. ISSN 1851-6297. ISSN 2362-3349 (EN LINEA). INSTITUCIÓN E INDIVIDUO EN TENSIÓN. EL PROCESO DE CAMBIO EN LA FORMACIÓN permanente del profesorado. Estudio de caso. Maria Soledad Manrique.

titucional que se produce en función de mantener lo instituido, y que, como tal, constituye un obstáculo al cambio que la docente ha iniciado.

Esta información resulta altamente relevante para pensar la formación permanente de los docentes. Dado el rol de productor de subjetividad que, como se ha mostrado, ejerce la institución en la que el docente se desempeña cotidianamente, es indispensable pensar dispositivos de formación en que se pueda trabajar no solo en el nivel intersubjetivo - grupal, sino también en el nivel institucional, en el cual no se había intervenido en el caso considerado.

\section{Referencias bibliográficas}

- Berenstein, I. (2004). Devenir otro con otros. Ajenidad, presencia, interferencia. Buenos Aires: Paidós.

- Bernstein, B. (1990). Poder, Educación y Conciencia. Sociología de la transmisión cultural. Barcelona: El Roure Editorial.

- Castoriadis, C. (1989). La institución imaginaria de la sociedad. Vol 2. Barcelona: TusQuests.

- Clot, Y. (2006). A funcao psicológica do trabalho. Río de Janeiro: Vozes.

- Fernandez, A. (2007). Las lógicas colectivas. Imaginarios, cuerpos y mutiplicidades. Buenos Aires: Biblos.

- Fernández, L. (1994). Instituciones Educativas. Dinámicas institucionales en situaciones críticas. Buenos Aires: Paidós.

- Foucault, M. (1981). Vigilar y castigar. Madrid: Siglo Veintiuno.

- Glaser, B. \& Strauss, A. (1967). The Discovery of Grounded Theory.Chicago: Aldine Publishing Company.

- Kerbrat - Orecchioni, C. (1986). La enunciación. De la subjetividad en el lenguaje. Buenos Aires: Hachette.

- Krippendorf, K. (1990). Método de análisis de contenido. Teoría y Práctica. Buenos Aires: Paidós.

- Manrique, M. (2014). Análisis del discurso. Aportes para la comprensión de las situaciones de enseñanza. Ficha de Cátedra. Buenos Aires: OPFyL. FFyL. UBA.

- Manrique, M. (2016). La formación docente como construcción negociada de un personaje y de un escenario. Revista Iberoamericana de Educación, 70 (2), pp. 9-27. Madrid. España.

- Manrique, M. \& Mazza, D. (2016). Formación y transformación subjetiva. Alcances y límites de un proceso de formación. Revista Educación, lenguaje y sociedad. IELES, XIII (13). pp. 1-21.

- Manrique, M. \& Sanchez Abchi, V. (2015). Teachers'practices and mental models. Transformation trough reflection on action. Australian Journal of Teacher Education, 40 (6), pp. 13-32.

- Mevorach, M. \& Strauss, S. (2012). Teacher Educators' In-Action Mental Models in Different Teaching Situations. Teachers and Teaching: theory and practice, 18(1), pp. 25-41.

- Taylor, S. \& Bogdan, R. (1987). Introducción a los métodos cualitativos de investigación. 
La búsqueda de significados. Barcelona: Paidós.

- Wilke, R. (2008). Developmental Changes in Preservice Teachers' Mental Models of Learning and Instruction. Electronic Theses, Treatises and Dissertations. The Florida State University: Florida, U. S. Consultado el 23 de Agosto de 2014 en la www: http:// diginole.lib.fsu.edu/cgi/viewcontent.cgi?article=5216\&context=etd Wilson.

- Zeichner, K. (1994). Research on teacher thinking and different views of reflective practice in teaching and teacher education. En I. Carlgren, G. Nadal, S. Vaage (Eds.). Teachers' Minds and Actions: Research on Teachers' Thinking and Practice (pp.9-27). London: Falmer Press. 